\section{Michigan Technological \\ 1885 University}

Michigan Technological University

Digital Commons @ Michigan Tech

\title{
Distributed Recycling Waste Polymer into RepRap Feedstock
}

Christopher Baechler

Queen's University - Kingston, Ontario

Matthew DeVuono

Queen's University - Kingston, Ontario

Joshua M. Pearce

Michigan Technological University

Follow this and additional works at: https://digitalcommons.mtu.edu/materials_fp

\section{Recommended Citation}

Christian Baechler, Matthew DeVuono, Joshua M. Pearce, (2013) "Distributed recycling of waste polymer into RepRap feedstock", Rapid Prototyping Journal, Vol. 19 Iss: 2, pp. 118 - 125.

http://digitalcommons.mtu.edu/materials_fp/29/ 


\title{
Distributed Recycling of Waste Polymer into RepRap Feedstock
}

\author{
Christian Baechler (1), Matthew DeVuono (1), and Joshua M. Pearce (2)
}

1. Department of Mechanical and Materials Engineering, Queen's University, Kingston, Ontario, Canada 2. Department of Materials Science \& Engineering and Department of Electrical \& Computer Engineering, Michigan Technological University, Houghton, MI 49931, USA

\begin{abstract}
:
Purpose: A low-cost, open source, self-replicating rapid prototyper (RepRap) has been developed, which greatly expands the potential user base of rapid prototypers. The operating cost of the RepRap can be further reduced using waste polymers as feedstock. Centralized recycling of polymers is often uneconomic and energy intensive due to transportation embodied energy. This paper provides a proof of concept for high-value recycling of waste polymers at distributed creation sites.
\end{abstract}

Approach: Previous designs of waste plastic extruders (also known as RecycleBots) were evaluated using a weighted evaluation matrix. An updated design was completed and the description and analysis of the design is presented including component summary, testing procedures, a basic life cycle analysis and extrusion results. The filament was tested for consistency of density and diameter while quantifying electricity consumption.

Findings: Filament was successfully extruded at an average rate of $90 \mathrm{~mm} / \mathrm{min}$ and used to print parts. The filament averaged $2.805 \mathrm{~mm}$ diameter with $87 \%$ of samples between $2.540 \mathrm{~mm}$ and $3.081 \mathrm{~mm}$. The average mass was $0.564 \mathrm{~g} / 100 \mathrm{~mm}$ length. Energy use was $0.06 \mathrm{kWh} / \mathrm{m}$.

Originality: This paper reports on the first technical evaluation of a feedstock filament for the RepRap from waste plastic material made in a distributed recycling device.

Practical Implications: The success of the RecycleBot further reduces RepRap operating costs, which enables distributed in-home, value added, plastic recycling. This has implications for municipal waste management programs as in-home recycling could reduce cost and greenhouse gas emissions associated with waste collection and transportation as well as the environmental impact of manufacturing custom plastic parts.

Keywords: Rapid prototyping; Open source; Polymer extrusion; Recycling; Waste plastic recycling; RepRap

Category: Technical

\subsection{Introduction}

Commercial rapid prototypers allow for accurate fabrication of products or scale models, are a useful production and design tool, and the development of additive manufacturing (AM) for rapid prototyping in a number of technologies has been substantial (Upcraft and Fletcher, 2003; Gibson, Rosen, and 
Stucker, 2010; Petrovic, et al., 2010; Gebhardt, et al., 2010; Crane, et al., 2011). Recently an open source (OS) model, the RepRap, has been developed which can be built for under \$1000, greatly expanding the potential user base of rapid prototypers. The RepRap was created by Adrian Bowyer and influenced by many contributors (Jones et al., 2011) including similar models such as the Fab@ home (Malone and Lipson, 2007). The RepRap is supported by an online wiki community with detailed assembly instructions for several variants of 3-D printers ${ }^{[1]}$. While OS models have limitations compared to commercial processes, they are capable of creating highly accurate parts. The specifications of the RapMan, a commercially available version of the RepRap are shown in Table 1, below. These machines could feasibly be used as a small-scale manufacturing or as an enabling tool for sustainable development (Pearce et al., 2010). Between 2008 and 2011, it is estimated that the number of RepRaps in use had increased from 4 to 4500 (Jones et al., 2011).

Table 1: RapMan 3.1 Single 3D printing specifications ${ }^{[2]}$

\begin{tabular}{|l|l|}
\hline \multicolumn{1}{|c|}{ Parameter } & \multicolumn{1}{c|}{ Tolerance } \\
\hline Build Size (x-axis / y-axis / z-axis) & $270 \mathrm{~mm} / 205 \mathrm{~mm} / 210 \mathrm{~mm}$ \\
\hline Z-axis resolution & $0.125 \mathrm{~mm}$ \\
\hline Print Tolerance & $\begin{array}{l}\text { x axis and y axis: greater of } \pm 1 \& \text { of object dimensions } \\
\text { or } \pm 0.2 \mathrm{~mm} \\
\text { z axis: } \pm \text { half the processed } \mathrm{z} \text { resolution }\end{array}$ \\
\hline Print Speed Extruded Volume & max $15 \mathrm{~mm}^{3} / \mathrm{s}$. \\
\hline Power Requirements & $60 \mathrm{~W}(5 \mathrm{~A}$ at $12 \mathrm{~V})$ \\
\hline
\end{tabular}

The operating cost of the RepRap can be further reduced by reducing the cost of the feedstock. Fabrication of feedstock from waste plastic would lower costs and reduce the environmental impact of rapid prototyping (Pearce et al., 2010). Further, extrusion of RepRap filament may provide incentive for distributed in-house recycling of plastic waste based on the preliminary economic analysis reported here. Currently, in-house recycling is marginal (e.g. using reclaimed objects in student art projects (TeacherVision, 2011)). The one growing exception is the household-scale recycling (composting) of organic waste, which still tends to be centralized (Åberg, et al., 1996; Goldstein, 2003; EPA, 2011). The cost and complexity of recycling most materials has historically favored centralized recycling with plastic recycling being a challenge for technical and social reasons (McDonald and Ball, 1998; Huang, et al. 2003; The Economist, 2007). Though favorable over alternatives, centralized recycling still has some negative environmental impacts (Bjorklund and Finnveden, 2005; Ross and Evans, 2001). In particular, the collection, transport and transfer (CTT) of recyclable waste entails significant greenhouse gas (GHG) emissions, contributing to the overall global warming potential of the recycling process (Eisted et al., 2009; Salhoffer et al., 2006). In one specific case, transportation and collection was found to account for more than half of process emissions (Metcalfe, 2008).

Waste plastic extrusion and OS 3D printing could also serve as a sustainable development tool (Pearce et al., 2010). Plastic waste is common in many developing communities (Al-Khatib et al., 2010; Muttamara et al., 1994) and informal waste recycling is sometimes conducted as an economic activity (Zia et al., 2008). A low-cost RecycleBot could serve to increase the product value of recycled waste in these settings. A similar project is currently under way in Argentina known as Waste for Life which provides technology for value added recycling of waste polymers into plastic-fibre composite sheets 
(Baillie, 2008). It should be noted, however, that before any sustainable development project is undertaken, an assessment of the social impacts of this technology should be undertaken to avoid unintentional impacts to environmental and social dynamics and assess the benefits to local populations.

Commercial extrusion of plastic utilizes a screw to move material through a heated barrel where it is compressed, melted, mixed and forced through a die (Rosato, 1997). Some groups have attempted to adapt these principles and construct a small-scale plastic extruder with varying success (RecycleBot, 2010; Braanker et al., 2010). One such device, which turns waste plastic into a growth medium for plants (Torcellini, 2010), has been modified here to create a new, semi-automated RecycleBot to prepare RepRap feedstock from household plastic waste such as bottles and laundry detergent containers.

A description and analysis of the semi-automated RecycleBot is presented here including component summary, testing procedures, a basic life cycle analysis and extrusion results. The filament was tested for consistency of density and diameter while measuring electricity consumption. Results of this preliminary proof of concept and technical evaluation of feedstock filament for the RepRap from waste plastic material using a distributed recycling device are evaluated and conclusions are drawn.

\subsection{Methodology}

\subsection{Design}

The design methodology incorporated examination of: i) commercial devices; ii) a literature review and; iii) similar open source projects. The following general desirable characteristics were identified for the extruder: i) quality and reliability, ii) simple design minimizing number and complexity of components; iii) economical; iv) low power requirements; v) automated; and vi) the ability to accept wide range of thermoplastics. Diametrical consistency $(2.8 \pm 0.2 \mathrm{~mm})$ was needed to ensure the filament could feed consistently into the 3D printer, while constant density was necessary to support a steady extrusion rate and high quality prints. A simple, low cost device will be more readily adopted by users. Maintaining low power requirements further increases the viability of the extruder in the Global South and is environmentally beneficial. Automation will increase productivity while acceptance of a wide range of thermoplastics is required to meet all prototyping needs. Finally, the extruder must be compatible with the 3D printer, producing the plastic filament used as feedstock for the RepRap. Producing granules, or other feedstock would require alterations to the RepRap extruding mechanism, which is beyond the scope of this work.

Three previous concepts were identified as a potential basis for the current design: 1) the RecycleBot hand-crank extruder (RecycleBot, 2010), 2) Tan/Nixon granular extruder (Tan and Nixon, 2007) and 3) Torcellini's growth medium extruder (Torcellini, 2010). These design concepts were evaluated with a weighted evaluation matrix based on the following criteria: i) cost; ii) ease of use; iii) automation; iv) adaptability to RepRap; v) quality and; vi) energy use. An optimal concept was thus chosen, refined and prototyped.

Testing was conducted with high density polyethylene (HDPE). HDPE is characterized as relatively stiff with high tensile strength compared to other polyethylenes (American Chemical Council, 2007). 
The engineering properties of HDPE are summarized in Table 2 (Khelif et al., 2008). Although other polymers exist within the household waste stream that are suitable for 3D printing, HDPE was chosen to build on the work of similar open source projects, most of which used HDPE (Braanker et al. 2010, RecycleBot 2010, Torcellini, 2010). It was also found to be more prevalent in the local waste stream than acrylonitrile butadiene styrene $(\mathrm{ABS})$ (chemical formula: $(\mathrm{C} 8 \mathrm{H} 8) \mathrm{x} \cdot(\mathrm{C} 4 \mathrm{H} 6) \mathrm{y} \cdot(\mathrm{C} 3 \mathrm{H} 3 \mathrm{~N}) \mathrm{z})$ and Poly(lactic acid) or polylactide (PLA) (chemical formula: C3H6O3), two polymers commonly used in OS 3D printing applications.

Table 2: Common engineering properties of HDPE (Khelif et al., 2008).

\begin{tabular}{|l|c|}
\hline \multicolumn{1}{|c|}{ Property } & Value \\
\hline Density $\left(\mathrm{kg} / \mathrm{m}^{3}\right)$ & 950 \\
\hline Thermal expansion factor $\left(10^{6} / \mathrm{K}\right)$ & $100-200$ \\
\hline Poisson's Ratio & 0.46 \\
\hline Friction factor & 0.29 \\
\hline Rockwell Hardness (shore) & $\mathrm{D} 60-73$ \\
\hline Elastic modulus (GPA) & $0.5-1.2$ \\
\hline Impact Resistance, IZOD $(\mathrm{J} / \mathrm{m})$ & $20-210$ \\
\hline
\end{tabular}

\subsection{Testing}

The extruder prototype was tested with HDPE and the following metrics were quantified: i) resultant filament consistency; ii) energy use per unit length of filament and iii) process time.

Consistency was determined by measuring filament diameter and mass per unit length from a $6.00 \pm 0.01 \mathrm{~m}$ sample of extruded filament. The filament was divided into 60 sections of $0.100 \pm 0.003 \mathrm{~m}$. Diameter was measured at the section midpoint using a micrometer $( \pm 0.0001 \mathrm{in} / 0.003 \mathrm{~mm})$. Section mass was determined using a digital scale $( \pm 0.0001 \mathrm{~g})$, and compared on the basis of mass per unit length $( \pm 0.001 \mathrm{~g} / 100 \mathrm{~mm})$.

The energy consumption was quantified using watt/electrical energy meters $( \pm 0.005 \mathrm{kWh})$. Data was recorded for each stage of filament production, including shredding $(\mathrm{kWh} / \mathrm{g})$, auger drive and heating. The energy use was measured for the extrusion of $11.41 \pm 0.05 \mathrm{~m}$ of filament, and averaged to determine the $\mathrm{kWh} / \mathrm{m}$ of filament produced. Shredding energy was incorporated by converting the measure of $\mathrm{kWh} / \mathrm{g}$ to $\mathrm{kWh} / \mathrm{m}$ as shown in equation 1 and 2 below. The energy density (energy per unit mass) of shredded material, $\mathrm{Q}$, is:

$$
Q=E_{s} / m_{w p}[k W h / g]
$$

Equation 1

where $E_{s}$ is the energy consumed during shredding and $m_{w p}$ is the mass of the waste plastic shredded. The energy consumed during shredding per meter of filament produced $E_{s / m}$ is:

$$
E_{s / m}=Q \times m_{l} \quad[k W h / m]
$$

Equation 2

where $m_{l}$ is the average mass per meter of filament.

Process time includes the time required to shred, heat and extrude filament. An average time was 
empirically determined for the shredding of $100 \mathrm{~g}$ of polymer (min). This included removing labels, cutting bottles into smaller pieces and grinding using a commercial office shredder. It did not include the time required for washing used bottles because of large variance in washing time based on cleanliness. Heating and extrusion time is divided into two components. The start-up time is defined as the time passed between start-up and initial extrusion. During this time, the barrel must heat up and plastic remaining from previous extrusions must re-melt. The extrusion time is defined as the average time required to produce a meter of filament as timed with a digital watch $( \pm 0.01 \mathrm{~s})$.

\subsection{Results}

\subsection{Design}

The Torcellini "aquaponics extruder" was modified and fabricated because of design strengths including: automation, RepRap compatibility and product quality. The prototype waste plastic extruder consists of 3/4" (inner diameter) piping divided into a gearing, hopper and heating section. Shredded plastic is fed into the hopper and transported to the heating section by a 3/4" - 17" ship bore auger driven by a windshield wiper motor. Power is transferred from motor to auger using a sprocket and chain drive system with a 2:1 gear ratio to decrease speed and increase torque. The motor has a stall torque of $30 \mathrm{Nm}$ and runs at $35 \mathrm{rpm}$ on the low speed setting. The gearing section of the extruder body houses the auger and also provides support for a thrust bearing and collar used to counter axial force encountered during transportation of the ground plastic. An exploded assembly diagram of the main extruder body is shown in Figure 1.

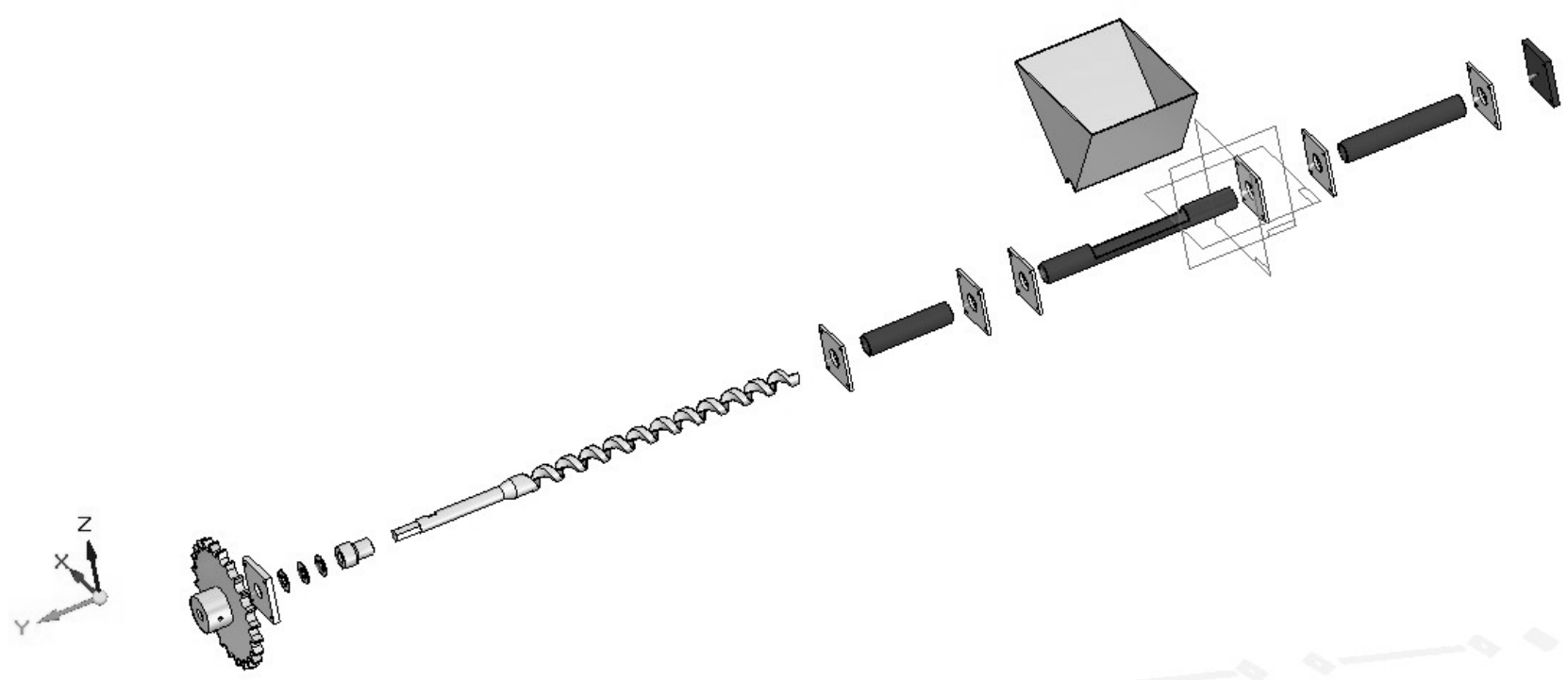

Figure 1: Exploded assembly diagram of the extruder. Visible are the gearing, hopper and heating sections, the auger, thrust bearing, collar and large sprocket.

Plastic pushed into the heating section is melted and forced through a die producing plastic filament. The heating zone consists of 14 gauge nichrome 80 wire wrapped around the barrel and secured with heat resistant Kapton tape. Furnace cement was applied between the piping and the uninsulated nichrome to prevent short circuiting through the pipe at high temperatures. This step can be avoided by using insulated nichrome wire. Fourteen gauge wire was chosen in an effort to create the heating zone 
with minimal power requirements. Wire temperatures of $225^{\circ} \mathrm{C}$ were achieved with $75 \mathrm{~W}$ of power $(15 \mathrm{~V}$, 5A). Temperature can be adjusted by altering the current passing through the nichrome wire. The section has one uniform heating zone. Presently, the heating section is uninsulated however adding insulation would likely improve performance and reduce start-up time and energy use, while making it more difficult to troubleshoot. Either a wood or metal base can be used to hold the extruder.

\subsection{Testing}

\subsubsection{Quality}

During testing, $11.41 \pm 0.05 \mathrm{~m}$ of filament was extruded. The first meter was removed because of inconsistent extrusion on start-up. The remaining filament was divided into two sections. Quality testing was conducted on a $6.00 \mathrm{~m}$ section of filament. The remaining $4.41 \mathrm{~m}$ was used for printing. Measurements for mass and diameter were conducted on 60 samples of $100 \pm 3 \mathrm{~mm}$. A histogram of diameter measurements is shown in Figure 2, below.

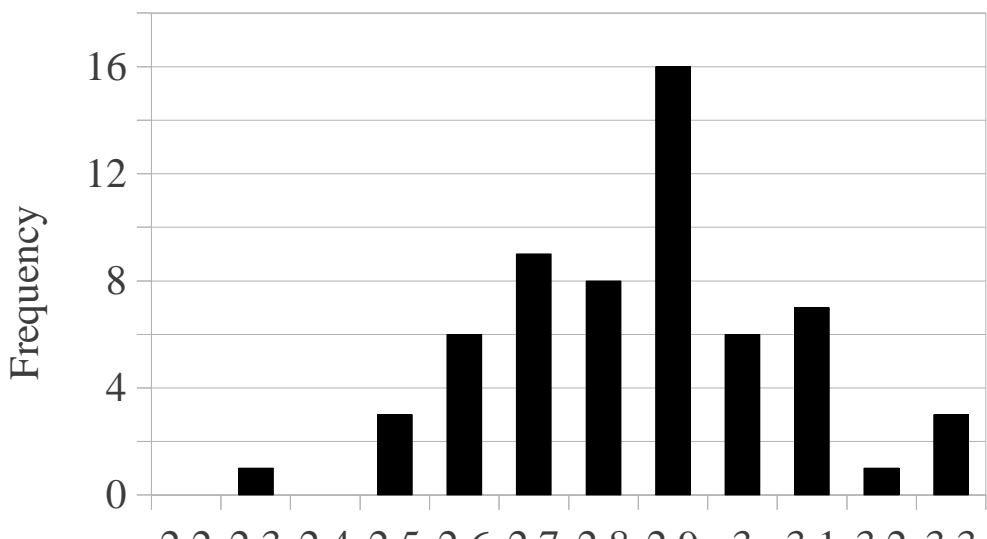

$\begin{array}{lllllllllllll}2.2 & 2.3 & 2.4 & 2.5 & 2.6 & 2.7 & 2.8 & 2.9 & 3 & 3.1 & 3.2 & 3.3\end{array}$

Diameter $[\mathrm{mm}]$

Figure 2: Diameter measurements taken at 100mm intervals over 6m of filament

Filament diameter ranged from $2.225 \mathrm{~mm}$ to $3.294 \mathrm{~mm}$ with an average measurement of $2.805 \pm 0.003 \mathrm{~mm}$.

The mass of each section, displayed in Figure 3, ranged from $0.437 \mathrm{~g} / 100 \mathrm{~mm}$ to $0.694 \mathrm{~g} / 100 \mathrm{~mm}$ of filament. Measurements were distributed evenly across this spectrum. The average mass was $0.564 \mathrm{~g} / 100 \mathrm{~mm}$. 


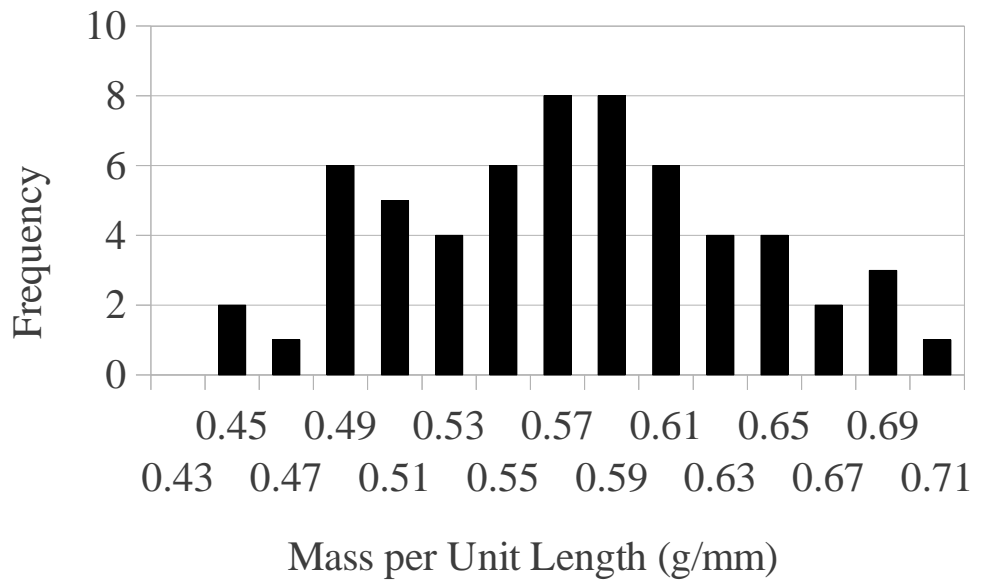

Figure 3: Mass of 100mm sections of filament from a 6 m long sample.

\subsubsection{Energy Consumption}

The peak power and measured energy consumption during each production stage is shown in Table 2 . Shredding energy was calculated as an average of four trials producing $2060 \pm 10 \mathrm{~g}$ of shredded plastic in total and converted to energy per meter of filament using Equation 2. Heating accounted for two thirds and the motor energy use about $1 / 3$ of the total energy use, while shredding energy consumption was negligible.

Table 3: Energy use at each stage of extruder process.

\begin{tabular}{|l|c|c|c|}
\hline $\begin{array}{c}\text { Power } \\
\text { Draw }\end{array}$ & $\begin{array}{c}\text { Peak Power } \\
{[\mathbf{W}]}\end{array}$ & $\begin{array}{c}\text { Energy per } \\
\text { Length } \\
\text { Filament } \\
{[\mathbf{k W h} / \mathbf{m}]}\end{array}$ & $\begin{array}{c}\text { Percent of } \\
\text { Energy per } \\
\text { Unit Length } \\
{[\%]}\end{array}$ \\
\hline Shredding & 128 & 0.0002 & 0.33 \\
\hline Motor & 66 & 0.02 & 33.22 \\
\hline Heating & 75 & 0.04 & 66.45 \\
\hline Total & 269 & 0.06 & 100 \\
\hline
\end{tabular}

These values of energy consumption are necessary for a life cycle analysis (LCA), which is a means of quantifying how much energy and raw material are used and how much (solid, liquid, and gaseous) waste is generated at each stage of a product's life. Ideally an LCA would include quantification of material and energy needed for (Pearce and Lau, 2002): raw material extraction, manufacturing of all 
components, use requirements, generation (if any -- e.g. photovoltaics), end of use (disposal or recycling), and the distribution/transportation in between each stage. A full LCA is beyond the scope of this paper, however, a direct comparison between the recycled feedstock created by the process described above and a virgin HDPE material can be made. As the mass per unit length of HDPE is $5.64 \mathrm{~g} / \mathrm{m}$ a $\mathrm{kg}$ of HDPE is $177.3 \mathrm{~m}$ of filament. The total energy use for filament production (including shredding, melting and extrusion) from Table 3 is $0.06 \mathrm{kWh} / \mathrm{m}$, which results in an embodied energy of $10.63 \mathrm{kWh} / \mathrm{kg}$ HDPE, which is $38.29 \mathrm{MJ} / \mathrm{kg}$. In comparison, the average embodied energy of virgin HDPE feedstock over 11 records is $79.67 \mathrm{MJ} / \mathrm{kg}$ (Hammond and Jones, 2008). It should be noted that this figure is HDPE material alone and there may be additional embodied energy for forming filament. It can thus be concluded that the recycled feedstock using the processes described here has a much lower embodied energy than virgin material. A more detailed LCA that compares distributed recycled HDPE filament production to large-scale centralized recycling facility product over different population densities is left for future work. This more detailed study could look carefully at embodied energy and emissions, take into account transportation and disposal, which would be particularly relevant in the developing world where recycling programs may be inefficient or nonexistent and virgin polymer may be in short supply.

\subsubsection{Time}

Time requirements were measured at each stage of the extrusion process. A total of $2060 \pm 10 \mathrm{~g}$ of plastic was shredded in $211 \mathrm{~min}$ or $10.27 \mathrm{~min} / 100 \mathrm{~g}$. Given $\mathrm{m}_{1}$ of extruded plastic, $100 \mathrm{~g}$ of shredded plastic should be sufficient to extrude $\sim 17.7 \mathrm{~m}$ of filament.

For the extrusion process, the start-up time was found to be $45 \pm 2 \mathrm{~min}$ when heating with $5 \mathrm{~A}$ and $15 \mathrm{~V}$, but was reduced to $25 \mathrm{~min}$ when supplying $10 \mathrm{~A}, 15 \mathrm{~V}$. Filament extrusion was not constant; however, the average rate was $90 \mathrm{~mm} / \mathrm{min}$.

\subsection{Discussion}

Several parts were successfully printed on a 3D printer as proof of concept for the viability of the use of the recycled polymer filament.

\subsection{Analysis}

From the initial samples, $65 \%$ was within the desired diametrical range of $2.28 \mathrm{~mm}$, while $87 \%$ fell between $2.540 \mathrm{~mm}$ and $3.081 \mathrm{~mm}$ in diameter. This is less consistent than commercially extruded filaments such as ABS from Makerbot at $2.27 \pm 0.01 \mathrm{~mm}$. Inconsistencies measured here are a result of a variable extrusion rate and manual drawing of filament from the die.

The mass per unit length of 60 samples was distributed between $0.437 \mathrm{~g} / 100 \mathrm{~mm}$ and $0.694 \mathrm{~g} / 100 \mathrm{~mm}$, a range of $0.257 \mathrm{~g} / 100 \mathrm{~mm}$ as can be seen in Figure 3. This range represents $46 \%$ of the average mass, found to be $0.564 \mathrm{~g} / 100 \mathrm{~mm}$. While the extruded filament worked when printing, this large variation can cause problems in print quality and further optimization of the system is required. The average $\mathrm{m}_{l}$ is 
close to expected values as HDPE of $950 \mathrm{~kg} / \mathrm{m}^{3}$ density should produce $\mathrm{m}_{1}=0.585 \mathrm{~g} / 100 \mathrm{~mm}$ for filament with a diameter of $2.8 \mathrm{~mm}$. The variation in mass can largely be explained by the corresponding change in diameter between sections.

The total electricity consumption required for filament construction was $0.060 \pm 0.05 \mathrm{kWh} / \mathrm{m}$ of filament. Excluding labor costs and using current residential electricity prices in the U.S. at 11.2 cents/kW-hr (EIA, 2011) a kg of HDPE feedstock would cost less than a dollar to fabricate. For comparison, the current cost of a kilogram of HDPE or ABS filament is between $\$ 37-\$ 43 . .^{[3]}$ These values are the retail rate of the filament, not the cost of production, which could be significantly lower as the 2011 U.S. prices for bulk purchase of polymer pellets ranged from $\$ 0.69 / \mathrm{kg}$ to $\$ 1.76 / \mathrm{kg}$ and $\$ 1.91 / \mathrm{kg}$ to $\$ 2.00 / \mathrm{kg}$ for HDPE and ABS respectively. ${ }^{[4]}$ It would be expected that the large-scale production of filament could have some energy efficiency benefits compared to the small systems described here, simply from surface to volume ratio heat loss reductions. Based on the raw material costs and the energy needs of production, it appears clear that the cost of production are currently very low compared to retail costs. Although values for the cost of production of the filament using modern large high-speed extruders is not available in the open literature, it is clear that in the current AM industry, the price of the filament even for the low-cost 3-D printers is significantly inflated. The widespread adoption of the RecycleBots described in this paper, should foster competition and a potential oversupply of filament on the market (e.g. RecycleBot owners could offer filament for sale on the web and the same time decreasing demand by providing for their own needs). Thus, except for rare exceptions (Chen and Riordan, 2008), just as in many cases in economic history as the competition and supply of a manufactured good increases, the costs can be expected to decrease. The existence of RecycleBots, therefore, should provide a significant downward price pressure for conventionally manufactured filament at the retail level.

The design performed well under most of its performance criteria. The extruder is simple to use, and construction of the device can be accomplished with basic metal working skills. The extruder can successfully extrude HDPE with $125 \mathrm{~W}$ of power, which is about the same power draw as the shredder. With proper temperature control, a wide range of thermoplastics can be extruded but further testing is needed to determine optimal settings for each.

Three deficiencies were observed in the current design. First, physical assistance was required to draw the filament from the extruder. This resulted in a wide variance of extrusion diameter due to inconsistent rates of pulling. Manually pulling also required constant user attention, reducing the benefits of automation. Two devices were created in an attempt to automatically draw the filament at a constant rate. One device used a motorized spool to coil the filament while the second employed a pinch wheel design to pull filament from the die.

These devices were ultimately unsuccessful due to the second extruder limitation - an inconsistent rate of extrusion. It was found that the rate of extrusion varied greatly over even short extrusion distances. This meant that neither device could not be calibrated to draw filament at an optimal rate, as they lacked the proper feedback mechanisms to adjust to changing extrusion speeds. At higher extrusion rates, it was possible to create a reasonably consistent product by manually drawing the filament.

This rate variance was most likely due to the third limitation of heterogeneous waste feedstock and methods of overcoming it include large batch mixing (blending) after shredding or extruding only from 
homogeneous sources. Extrusion was greatly affected by the size and type of shredded plastic fed in to the machine. Thin, light pieces of HDPE, such as those sourced from milk jugs, did not extrude well as they were not easily drawn into the heating section of the extruder. Heavier pieces, sourced from laundry detergent and shampoo containers performed much better and extruded at a faster, more constant rate. Extrusion rate was further increased by cutting the feedstock into small bits $(\leq 5 \mathrm{~mm} \mathrm{x}$ $5 \mathrm{~mm}$ ), which greatly increased the extrusion rate, but did not improve consistency. Further work is necessary to make the extrusion rate more consistent and fully automate the extrusion process. One suggestion is to extend the auger further into the heating section to have control over the movement of plastic further into the process.

Recycled plastic was successfully used in an OS 3D printer to make increasingly successful parts. Successive part generations showed increased accuracy, higher density and reduced delamination as extrusion rate, layer thickness and fill percentage were optimized. Thermal warping was also reduced as temperature settings were improved and surface finish was enhanced by adjusting settings for shell layers. Parts created with recycled HDPE have not matched the quality of parts printed from commercially-available virgin ABS on the same machine. A number of factors contribute to this discrepancy: i) HDPE is more difficult to work with than ABS because of it is more vulnerable to the effects of thermal warping during printing ${ }^{[5]}$, ii) ABS has been used on RepRaps and variants in thousands of locations for years, during which time the printing settings have been progressively optimized, and iii) the variation in diameter and $m_{l}$ of filament make it difficult to print at a consistent rate. Initial experimentation with print settings has greatly contributed to an improved product and it is believed that further experimentation with these settings, as well as increased automation of future RecycleBot variants, the quality of prints will continue to improve. The addition of a heated print bed is also recommended to limit the effects of thermal warping on printed parts.

\subsection{Implications}

The success of this device further enhances RepRap affordability by reducing operating costs substantially. This work therefore supports acceleration of the already rapid diffusion of RepRap, home manufacturing, distributed manufacturing, “AM at home” or OS 3D printing concepts. It also reduces waste associated with OS 3D printing as failed prints and excess filament can be recycled and reused in RepRaps. Research has been conducted into the degradation of crystalline additive manufacturing materials, but until now similar studies pertaining to HDPE and other amorphous polymers have been deemed unnecessary, however with the growing prevalence of OS 3D printers, these materials must be considered.

With a growing user base, shrinking cost and an increasingly user friendly interface, OS 3D printing has major implications in small scale manufacturing and design. By further reducing operating costs and negating the need for shipping from a third party, recycled filament can further promote adoption of OS 3D printers. Low price machines could make rapid prototyping more accessible for educational purposes, small businesses and domestic use.

In addition, filament extrusion enables in-home, value-added plastic recycling thereby avoiding the GHGs and economic costs associated with municipal recycling programs by bypassing CTT. In their analysis of various recycling management systems, Salhofer et al. concluded that transport accounted for up to $10 \%$ of process GHG emissions in HDPE film recycling (2006). Eisted et al. quantified CTT 
as resulting in 9.4 to $368 \mathrm{kgCO}_{2}$ equiv./tonne of waste depending on various factors (2009). It should be noted that these studies are not identical materials to our product and that a more detailed LCA is needed in the future. However, eliminating the need for collection and transportation of polymer waste would clearly reduce environmental impact.

\subsection{Future Work}

In addition to the improvements needed to automate the RecycleBot with a constant rate of extrusion discussed above, research is needed to develop an inexpensive, open source household-scale plastic shredder. Plastic used in testing was shredded with a commercially available office shredder, which was time consuming and created an inconsistent product.

To show the viability of recycled feedstock for use in products which require high-quality materials, the engineering properties of recycled polymers should be evaluated and compared with those of virgin polymers and the impact of multiple extrusion cycles should also be examined as plastic is viable for only a finite number of cycles (Karahaliou and Tarantili, 2009). These tests can also include the quality of the recycled HDPE filament in terms of circularity, which is highly relevant for the RepRap deposition process. No known testing has been conducted in the context of 3D printing.

The potential of lower environmental impact of a distributed network of RecycleBots is based on the idea that this approach is more efficient than the use of large centralized (commercial) polymer recycling facilities because of the substantial CCT demanded by centralized recycling. The necessary embodied energy of transportation demanded by the centralized approach make it inherently inefficient. This CCT inefficiency is enhanced in the case of polymers because of the relatively low density when compared to other recyclable materials. However, normally large-scale centralized processes tend to be more efficient (both financially and in terms of energy consumption as mentioned above) due to economies of scale, whether in recycling or in production of even complex modern products such as solar photovoltaics (Prattern, 1971; O’Sullivan and Sheffrin, 2003; The Economist, 2007; Pearce, 2008). Thus it is clear that a more thorough investigation is needed to determine if these economies of scale exist in polymer recycling and whether they are outweighed by the advantages of localized recycling. As such, a full life cycle analysis of waste plastic feedstock as discussed above should be conducted and compared to centralized recycling, which accounts for multiple extrusion cycles and ultimately, feedstock disposal. The results of this study will be geographically dependent as travel distance, type of vehicle and fuel, and emissions intensity of the grid depend on the region investigated. This will give a better indication of the true environmental impacts of this technology. Finally, tests should be conducted on the device to quantify the off-gassing of volatile organic compounds and other harmful substances during plastic melting. This has been done for various commercial processes (Patel et al., 1995) and has found that worker exposure to harmful substances is below health and safety standards (Forrest et al., 1995). However, the in-house process is much less controlled and should be independently tested. 


\subsection{Conclusions}

A household-scale semi-automated waste plastic extruder was created by modifying existing designs and successfully extruded filament for use in an open source 3D printer. Recycled plastic from the extruder was successfully used in an OS 3D printer to make increasingly successful parts. Filament was extruded at an average rate of $90 \mathrm{~mm} / \mathrm{min}$ with average diameter of $2.8 \mathrm{~mm}$. While some product variance occurred, $87 \%$ of samples had an acceptable diameter and the average mass of extruded filament was $0.564 \mathrm{~g} / 100 \mathrm{~mm}$ length. Energy use was $0.06 \mathrm{kWh} / \mathrm{m}$, which is significantly less embodied energy than virgin HDPE and makes filament extrusion at home roughly 40 times more economical in terms of energy than purchasing filament commercially. By further reducing operating cost, and negating the need for shipping from a third party, recycled filament can help grow the 3D printing community. It may also serve as an alternative source of income through value added recycling in the third world and as motivation for in-house recycling of plastic waste.

\section{References}

Åberg, H., Dahlman, Sven, Shanahan, H., Säljö, R. (1996). Towards sound environmental behaviour: exploring household participation in waste management. Journal of Consumer Policy, vol. 19, pp. 45-67.

Al-Khatib, I.A., Monou, M., Abu Zahra, A.S.F., Shaheen, H.Q. \& Kassinos, D. (2010), "Solid waste characterization, quantification and management practices in developing countries. A case study:Nablus district - Palestine", Journal of environmental management, vol. 91 no. 5, pp. 1131-1138.

American Chemistry Council, (2007) "Plastic Packaging Resins.” American Chemistry Council. Viewed: April 12, 2011. available at: http://www.americanchemistry.com/s_plastics/ bin.asp?CID=1102\&DID=4645\&DOC=FILE.PDF|available. (accessed 22 June 2011).

Baillie, C. (2008), "Waste for Life: Student learning through international development projects. Who pays and who benefits?", Materials Today, vol. 11 no. 10, pp. 6.

Bjorklund, A., and Finnveden, G., (2005), "Recycling Revisited-Life Cycle Comparisons of Global Warming Impact and Total Energy use of Waste Management Strategies," Resources, Conservation \& Recycling, vol. 44 no. 4, pp. 309-317.

Braanker, G. B., Duwel, J. E. P., Flohil, J. J., (2010), "Developing a Plastics Recycling Add-on for the RepRap 3D-Printer," available at: http://reprapdelft.files.wordpress.com/2010/04/reprapgranule-extruder-tudelft1.pdf, (accessed 22 June 2011).

Chen, Y., Riordan, M.H. (2008). "Price-Increasing Competition", The RAND Journal of Economics , vol. 39, no. 4, pp. 1042-1058. 
Crane, N.B., Tuckerman, J., Nielson, G.N., (2011) "Self-assembly in additive manufacturing: opportunities and obstacles", Rapid Prototyping Journal, Vol. 17, Iss. 3, pp. 211-217.

The Economist (2007). "Case history: The truth about recycling", The Economist, Technology Quarterly: Q2 2007. Available: http://www.economist.com/node/9249262 (accessed Dec. 8, 2011).

Eisted, R., Larsen, A. \& Christensen, T. (2009), "Collection, transfer and transport of waste: accounting of greenhouse gases and global warming contribution", Waste Management \& Research, vol. 27 no. 8 , pp. 738-745.

Energy Information Adminstration (EIA), (2011). "Average Retail Price of Electricity to Ultimate Customers by End-Use Sector, by State" Table 5.6. available at: http://www.eia.gov/cneaf/electricity/epm/table5 6 a.html, (accessed 23 June 2011).

Environmental Protection Agency (EPA), (2011). "Wastes - Resource Conservation - Reduce, Reuse, Recycle - Composting" available at: http://www.epa.gov/osw/conserve/rrr/composting/index.htm (accessed 9 Dec 2011).

Forrest, M. J., Jolly, A. M., Holding, S. R., (1995),"Emissions from Processing Thermoplastics", The Annals of Occupational Hygiene, vol. 39 no. 1, pp. 35-53.

Gebhardt, A., Schmidt, F.M., Hötter, J.S., Sokalla,W., Sokalla, P. (2010) “Additive Manufacturing by selective laser melting the realizer desktop machine and its application for the dental industry”, Physics Procedia, vol. 5, Part B, pp. 543-549.

Gibson, I., Rosen, D.W., Stucker, B. (2010) Additive Manufacturing Technologies: Rapid Prototyping to Direct Digital Manufacturing, Springer: New York.

Goldstein, N. (2003) "Solid waste composting trends in the United States", Biocycle,vol. 44, pp. 38-44.

Hammond, G.P., Jones, C.I., 2008, "Embodied energy and carbon in construction materials," Proceedings of the Institution of Civil Engineers - Energy, 161 (2), pp. 87-98.

Huang, C.H.,Ting, C.Y., Chang, S.M., Reu, R. (2003). "Institutional innovation and pricing scheme for sustainable waste recycling in Taiwan," In C.H. Liu, J.R. Yeh, and C.H. Huang eds., New Challenges for Sustainable Development in Millennia (Chung-Hua Institution for Economic Research, Taipei), pp. 279-318.

Karahaliou, E. -., and Tarantili, P. A., (2009), "Stability of ABS Compounds Subjected to Repeated Cycles of Extrusion Processing," Polymer Engineering \& Science, vol. 49 no. 11, pp. 22692275. 
Khelif, R., Chateauneuf, A. \& Chaoui, K. (2008), "Statistical analysis of HDPE fatigue lifetime", Meccanica, vol. 43, no. 6, pp. 567-576.

Jones, R., Haufe, P., Sells, E., (2011), "RepRap - the Replicating Rapid Prototyper," Robotica, vol. 29 no. 1, pp. 177-191.

Malone, E., and Lipson, H., (2007), "Fab@Home: The Personal Desktop Fabricator Kit," Rapid Prototyping Journal, vol. 13 no. 4, pp. 245-255.

McDonald, S., Ball, R. (1998). "Public participation in plastics recycling schemes", Resources, Conservation and Recycling, vol. 22, no. 3-4, pp, 123-141.

Metcalfe, P. (2008). "Audit of the Kerbside Recycling Services." The London Borough of Camden. Energy Audit Camden Report 3. ADAS, Wolverhampton, UK.

Muttamara, S., Visvanathan, C. \& Alwis, K.U. (1994), "Solid Waste Recycling And Reuse In Bangkok", Waste Management \& Research, vol. 12, no. 2, pp. 151-163.

Patel, S. H., and Xanthos, M., (1995),"Volatile Emissions during Thermoplastics processing-a Review", Advances in Polymer Technology, vol. 14 no. 1, pp. 67-77.

Pearce, J. M. (2008). “Industrial Symbiosis for Very Large Scale Photovoltaic Manufacturing”, Renewable Energy, vol. 33, pp. 1101-1108.

Pearce, J. and Lau, A. (2002). "Net Energy Analysis For Sustainable Energy Production From Silicon Based Solar Cells", Proceedings of American Society of Mechanical Engineers Solar 2002: Sunrise on the Reliable Energy Economy, editor R. Cambell-Howe, 2002.

Pearce, J. M., Morris Blair, C., Laciak, K. J., Andrews, Nosrat, A., Zelenika-Zovko, I., (2010). “3-D Printing of Open Source Appropriate Technologies for Self-Directed Sustainable Development", Journal of Sustainable Development, vol. 3 no. 4, pp. 17-29.

Petrovic, V., Gonzalez, J.V.H., Ferrando, O.J., Gordillo, J.D., Jose Ramón Blasco Puchades, J.R.B., Griñan, L.P., (2010 ). “Additive layered manufacturing: sectors of industrial application shown through case studies", International Journal of Production Research, vol. 49, Iss. 4, pp. 10611079 .

Prattern, C.F. (1971). Economies of scale in manufacturing industry. Cambridge, England: University of Cambridge Press.

RecycleBot Team. "RecycleBot," May-June 2010, RecycleBot blog, available at: http://recyclebot.tumblr.com/archive. (accessed 22 June 2011).

Rosato, Dominick (1997). Plastics Processing Data Handbook (2nd Edition). Springer - Verlag. 
Ross, S. \& Evans, D. (2003), "The environmental effect of reusing and recycling a plastic-based packaging system", Journal of Cleaner Production, vol. 11 no. 5, pp. 561-571.

Salhofer, S., Schneider, F., and Obersteiner, G., (2007), "The Ecological Relevance of Transport in Waste Disposal Systems in Western Europe," Waste Management, vol. 27 no. 8, pp. S47-S57.

O’Sullivan, A., Sheffrin, S. M. (2003). Economics: Principles in action. Pearson:Prentice Hall.

Tan, A., Nixon, T. (2007), "Rapid Prototype Manufacturing System", The University of Adelaide, Adelaide, Australia, available at: http://www.fabathome.org/wiki/uploads/c/cd/Rapid Prototype Manufacturing System Timothy Nixon \& Adrian Tan 2007.pdf (accessed 23 June 2011).

TeacherVision (2011), "Recycled Art" Available at: http://www.teachervision.fen.com/recycling/lessonplan/3276.html (accessed Dec. 9, 2011).

Torcellini, R., (2010), "Plastic extruder for growing media," . The Adventures of Bigelow Brook Farm blog. Available at:. http://web4deb.blogspot.com/2010/12/plastic-extruder-for-growingmedia.html. (accessed 12 April 2011).

Upcraft, S., Fletcher, R., (2003), "The Rapid Prototyping Technologies," Assembly Automation, vol. 23 no. 4, pp. 318-330.

Zia, H., Devadas, V. \& Shukla, S. (2008), "Assessing informal waste recycling in Kanpur City, India", Management of Environmental Quality, vol. 19, no. 5, pp. 597-612.

\section{End notes}

[1] http://reprap.org/wiki/Main Page., Multiple contributors, RepRap wiki, Accessed: April 24, 2011.

[2]

http://www.bitsfrombytes.com/sites/www.bitsfrombytes.com/files/downloads/RapMan31 Specs A4.pd f., RapMan 3.1 Technical Specifications, Bits from Bytes, Accessed: September 19, 2011

[3] http://store.makerbot.com/plastic.html Plastic for Printing. Accessed June 22, 2011. http://www.bitsfrombytes.com/catalog/materials Materials. Accessed July 13, 2011.

[4] http://www.worldscrap.com/modules/price/index.php World Scrap. 2011. "North American Recycled Plastics Prices (US cents per pound)". Accessed Dec. 9, 2011.

[5] http://wiki.bitsfrombytes.com/index.php/HDPE Bits from Bytes wiki. Accessed: April 24, 2011. 


\section{Acknowledgements}

The authors would like to acknowledge A. Bryson and N. Alazzam for technical assistance.

Christian Baechler

Department of Mechanical and Materials Engineering, Queen's University, Kingston, Ontario, Canada

baechler.christian@gmail.com

Christian Baechler is a research associate at Queen's Applied Sustainability Research group, where his academic interests include sustainable development and environmental applications of engineering.

Matthew DeVuono

mdevuono@gmail.com

Department of Mechanical and Materials Engineering, Queen's University, Kingston, Ontario, Canada

Matthew DeVuono is a research associate at Queen's Applied Sustainability Research group, where his research focuses on open source hardware design and sustainable development.

\section{Corresponding author:}

Joshua M. Pearce

Department of Materials Science \& Engineering and Department of Electrical \& Computer Engineering, Michigan Technological University, Houghton, MI 49931, USA

pearce@mtu.edu

Mailing address: 601 M\&M Building, 1400 Townsend Drive, Houghton, MI 49931-1295

ph:906-487-1466

Dr. Joshua M. Pearce received his Ph.D. in Materials Engineering from the Pennsylvania State University. He then developed the first Sustainability program in the Pennsylvania State System of Higher Education as an assistant professor of Physics at Clarion University of Pennsylvania and helped develop the Applied Sustainability graduate program while at Queen's University, Canada where he headed the Queen's Applied Sustainability Research Group. He currently is an Associate Professor cross-appointed in the Department of Materials Science \& Engineering and in the Department of Electrical \& Computer Engineering at the Michigan Technological University. His research concentrates on the use of open source appropriate technology to find collaborative solutions to problems in sustainability and poverty reduction. 